JSBED

15,2

304

\title{
Creativity in entrepreneurship education
}

\author{
Daniel Yar Hamidi
}

Center for Entrepreneurship and Business Design, University College of Borås, Borås, Sweden

Karl Wennberg

Center for Entrepreneurship and Business Creation, Stockholm School of Economics, Stockholm, Sweden, and

\author{
Henrik Berglund \\ Department of Technology Management and Economics, \\ Chalmers University of Technology, Göteborg, Sweden
}

\begin{abstract}
Purpose - The purpose of this paper is to use social cognitive theory to investigate entrepreneurial intent among participants in graduate entrepreneurship programs. Specifically, the authors test whether students' creative potential is related to their intention to engage in entrepreneurship.

Design/methodology/approach - Theoretically derived hypotheses are tested using multiple and ordinal regression analyses.

Findings - High scores on a creativity test and prior entrepreneurial experiences are positively associated with entrepreneurial intentions, whereas perception of risks has a negative influence.

Research limitations/implications - The authors' theoretical predictors of entrepreneurial intention received strong support, indicating that creativity should be considered in models of entrepreneurial intentions. However, the use of intentions as dependent variable has its own weaknesses in that it may not distinguish between "dreamers" and "doers".

Practical implications - The findings indicate that exercises in creativity can be used to raise the entrepreneurial intentions of students in entrepreneurship education. Heterogeneity in creative styles among students also points to the problems of a "one-size-fits-all" approach to entrepreneurship education.
\end{abstract}

Originality/value - The paper is the first to investigate the importance of creativity in entrepreneurship education and theoretical models of entrepreneurial intentions.

Keywords Entrepreneurialism, Education, Students

Paper type Research paper

\section{Introduction}

This paper contributes to our understanding of entrepreneurial behavior by showing that creativity is an important antecedent of entrepreneurial intentions. By entrepreneurial intentions we mean "a conscious state of mind that directs attention (and therefore experience and action) toward a specific object (goal) or pathway to achieve it (means)" (Bird, 1989, p. 8). Several empirical studies have found that a

Journal of Small Business and Enterprise Development

Vol. 15 No. 2, 2008

pp. $304-320$

(c) Emerald Group Publishing Limited $1462-6004$

DOI 10.1108/14626000810871691
The authors are grateful to Ecaterina Panasenco and Jurate Stanaityte for help with collecting the data. Frédéric Delmar provided helpful criticism on an earlier draft of this paper. Errors are the authors' alone. 
person's intention to become an entrepreneur offers the best predictor of her actually engaging in entrepreneurship in the future (Delmar and Davidsson, 2000; Krueger et al., 2000). Building on more general models, entrepreneurial intentions are typically considered to be formed by a person's attitude toward entrepreneurship, prevailing social norms attached to entrepreneurship, and the person's level of self-efficacy.

A factor that previously has not been considered in intention-based models is creativity. Yet entrepreneurship and innovative behavior have long been associated with creativity (Amabile, 1996; Nyström, 1993), and recent literature suggests that creative individuals are more likely to engage in entrepreneurial behavior (Ward, 2004). To the best of our knowledge, this conjecture has not yet been tested empirically. This paper offers the first comprehensive test of the relationship between creativity and entrepreneurial intentions. We investigate three graduate programs in entrepreneurship with the common attribute of training exercises in creativity and in generation of new ideas. To this end, we draw upon established theories of career choice and entrepreneurial intentions. We use a well-established creativity test to measure students' creative dispositions, at the same time testing prior known antecedents of entrepreneurial intention.

We found that high scores on the creativity test yielded a strong positive effect on entrepreneurial intentions, findings which are substantiated through various statistical models. We offer theoretical implications for research on entrepreneurship education and entrepreneurial intentions. Specifically, the study indicates that creative disposition should be added to models of entrepreneurial intentions. We also discuss practical implications for curriculum development in entrepreneurship programs, an area where empirical research is much needed.

\section{Theory and hypothesis development}

Entrepreneurship research has long examined the vast impact of personal history and social context on the propensity to engage in entrepreneurship by starting one's own business (Katz, 1992). Previous research illustrates that the theory of planned behavior can be used to predict employment status choice intentions (Kolvereid, 1996). Employment status choice intentions were defined by Katz (1992) as "the vocational decision process in terms of the individual's decision to enter an occupation as a salaried individual or as self-employed." Kolvereid (1996) argued that the greater a person's perceived behavioral control, the stronger is that person's intention to become self-employed. Perceived behavioral control in turn corresponds to perceived feasibility, one of the key factors of self-efficacy. Self-efficacy has been found to greatly influence entrepreneurial behavior (Krueger et al., 2000) and strengthening entrepreneurship students' self-efficacy is therefore seen as a key tool in entrepreneurship education to enhance students' entrepreneurial intentions (Fayolle, 2005).

\section{Entrepreneurship education in universities}

The latest decades have seen a tremendous rise in entrepreneurship education at universities around the globe. Solomon and Fernald (1991) analyzed data from three surveys on entrepreneurship education conducted by the US Small Business Administration, showing that among the universities who responded to the surveys, the number of new courses in entrepreneurship grew from 25 in 1979 to 107 in 1986, an
Creativity in entrepreneurship education

305 
JSBED

15,2

306 increase of 428 percent. Later years have seen an even larger increase, with over 25 endowed professorships in entrepreneurship in the US (Busenitz et al., 2003). In Europe, a recent survey among 164 of the largest business schools revealed that over 42 percent have established a specific entrepreneurship centers (Wilson, 2004) aimed at meeting what has been called "the move from the managed economy to the entrepreneurial economy" (Thurik and Wennekers, 2004).

What, then, are the general characteristics of entrepreneurship education in universities? A study of fifteen leading US entrepreneurship education programs (Hills, 1988) found that the primary goal for the majority of the programs was to increase the awareness and understanding of entrepreneurship as a process. The second major goal was to increase students' awareness of entrepreneurship as a career possibility. In regard to curriculum and practical education, the programs tried to increase students' awareness of how different management disciplines such as marketing, finance and accounting can be integrated when focusing on developing new ventures. Similar conclusions have also been reached by other surveys of entrepreneurship education programs in the US (Solomon et al., 2002; Zeithaml and Rice, 1987) as well as in Europe (Johannisson et al., 1998). Yet it remains to be investigated what specific parts of university entrepreneurship education programs are most effective to raise entrepreneurial intentions. The foremost pedagogical tool in many entrepreneurship programs seems to be having students learn how to write a business plan (Hills, 1988; Johannisson et al., 1998). There are both theoretical and practical reasons to move beyond the focus on business planning to a focus on other activities that can be key ingredients of future entrepreneurship programs.

In the current study we therefore examine three new, comparatively small, but in our view very ambitious entrepreneurship programs. All of the three programs try to increase students' awareness of entrepreneurship as a career possibility, but also include various practical training modules. Specifically, all three programs include training session in acting and thinking creatively, using a problem-based learning approach where students develop new and creative solutions to business ideas and eventually, in some cases, actually start new ventures during the educational program. Since entrepreneurial career theory (e.g. Kolvereid, 1996) has highlighted the importance of perceiving entrepreneurship as a viable and attractive career path for a person to engage in entrepreneurship, and since most international surveys indicate that this is also a key feature of most entrepreneurship education programs, this study will specifically investigate how entrepreneurship programs can affect students' entrepreneurial intentions.

\section{Effects of education on entrepreneurial intentions}

Entrepreneurial intention has been described as "a conscious state of mind that directs attention (and therefore experience and action) toward a specific object (goal) or pathway to achieve it (means)" (Bird, 1989, p. 8). Researchers typically trace entrepreneurial intentions to three general factors (Krueger et al., 2000). First, intentions are triggered by a person's attitude towards the behavior. This is seen as the weighted sum of perceived consequences and the likelihood of different outcomes of the behavior, including intrinsic rewards. The second factor is perceived social norms. This means that the beliefs of relevant groups and actors, such as family, friends, colleagues and customers, will affect the intentions of the entrepreneur (Davidsson, 
1991). The third factor is that a person's self-efficacy will influence intentions. Self-efficacy has been found to greatly influence entrepreneurial behavior, and improving the perceived feasibility of certain courses of action is therefore seen as vital to encourage increased entrepreneurial intentions (Krueger et al., 2000). Prior research indicates that not enough is known about the effects of different entrepreneurship programs on students' subsequent entrepreneurial behavior, although participation in such programs does seem to raise entrepreneurial intentions. Souitaris et al. (2007) surveyed 124 science and engineering students enrolled in an entrepreneurship program at one British and one French university, finding that the programs raised some entrepreneurial intentions among the students. Specifically, it was found that many students had experienced key moments of inspiration that drastically changed their "heart and mind" and made them consider becoming entrepreneurs. Considering that education is a given choice in itself, the starting point has to be that entrepreneurship students would be expected to be more likely than other students to consider starting their own business, because of self-selection into an entrepreneurship program (Storey, 2000):

H1. Entrepreneurship students are more likely than the other student groups to consider starting their own business in the future.

\section{Creativity and entrepreneurial intentions}

We have concluded that there seems to be ample international evidence that participating in an entrepreneurship program can raise students' entrepreneurial intentions. However, except for the recent study by Souitaris et al. (2007) there is little documented evidence of what specific factors within the programs are effective in raising entrepreneurial intentions. Since research often highlights creativity and novel solutions as a key part of the entrepreneurial process or as a characteristic of entrepreneurial behavior, and a common attribute in the three entrepreneurship education programs investigated in this paper is a focus on training exercises in acting creatively and generating new ideas, we consequently aim to investigate whether creativity can indeed raise entrepreneurial intentions.

There is a long tradition of describing entrepreneurship and innovative business behavior as an act of creativity (Amabile, 1996; Ward, 2004) and the two are often used synonymously. The connection can be found in the idea that a critical part of entrepreneurship is the newness and novelty (Davidsson, 2002) that can affect the market process. Entrepreneurs must come up with ideas for new goods or services that can be brought to a market, and having identified such, they must figure out how to effectively carry out this process. Because novelty and effectiveness are the hallmarks of creative ideas (Amabile, 1996), we expect that students' creative dispositions should affect their eagerness to engage in entrepreneurship:

H2. Creativity is positively related to students' intention to start their own firm.

\section{Prior evidence of entrepreneurial intentions}

To investigate the role of creativity and other educational efforts in entrepreneurial intentions, we need to control for other factors that prior research has found to affect entrepreneurial intentions. One key factor that is generally considered as the strongest positive predictor of entrepreneurial intention is whether an individual has some earlier
Creativity in entrepreneurship education

307 
JSBED

15,2

308 exposure to entrepreneurship. This has been explained by the increased knowledge and experience that follow from being an alumnus entrepreneur, making it easier for the person to assess the possibilities of starting a new firm (Delmar and Davidsson, 2000).

H3. Students are more likely to consider starting their own business in the future if they have some prior experience of starting their own firm.

In addition to the importance of earlier experiences of entrepreneurial activities, it has been pointed out that individuals with a close relation to someone with entrepreneurial experience will be more likely to try their wings as self-employed. In particular, it is known that a large proportion of entrepreneurs have parents who themselves were entrepreneurs. Two explanations for this pattern are that parents can act as role models (Delmar and Davidsson, 2000), and that there is a transfer of entrepreneurial skills from parents who expect their children to eventually take over the firm (Westhead, 2003). We could expect both factors to increase the intention of a young student to engage in future entrepreneurship:

$H 4 a$. Students are more likely to consider starting their own business in the future if they have parents or siblings with entrepreneurial experience.

It has also been suggested that research on why individuals engage in entrepreneurship should address potential differences in interest with respect to the source of the family background - for example, parental versus others, or immediate family versus extended family (Delmar and Davidsson, 2000). We therefore also hypothesize:

$H 4 b$. Students are more likely to consider starting their own business in the future if they have relatives or close friends with entrepreneurial experience.

\section{Effects of risk perception on entrepreneurial intention}

Entrepreneurship is inherently risky compared with working in an established business, and most definitions of an "entrepreneur" emphasize the risk willingness of these individuals. That is, they are usually described as risk-takers who attempt to achieve fast enterprise growth and above-average profits. In accordance with social cognitive intention theory, Palich and Bagby (1995) argue that entrepreneurs may not actually prefer to take risks; rather they simply tend to associate business situations with cognitive categories that suggest more favorable attributes. Thus, risk propensity can be treated as a personal aptitude for optimism.

H5. A lower perception of financial risk of becoming self-employed will be positively associated with students' intention to become self-employed.

\section{Entrepreneurial self-efficacy}

Self-efficacy is a broad social cognitive concept elaborated by Bandura (1986): it is the individual's cognitive estimate of his or her capabilities to mobilize the motivation, cognitive resources, and courses of action needed to exercise control over events in his or her life. Entrepreneurial self-efficacy refers to the strength of an individual's belief that he or she will or will not be able to successfully perform the roles and tasks of an 
entrepreneur (Boyd and Vozikis, 1994). The role of entrepreneurial self-efficacy has been emphasized as a key antecedent in starting one's own business by, among others, Boyd and Vozikis (1994), Krueger and Brazeal (1994) and Chen et al. (1998). From the theory of self-efficacy, it follows that individuals who discard entrepreneurship as a career option do so not because they necessarily lack the abilities needed, but because they believe themselves to lack these. And vice versa, higher awareness of one's capabilities in coping with entrepreneurial tasks will lead to a stronger motivation to start on one's own:

H6. A higher perception of entrepreneurial self-efficacy will be positively associated with students' intention to start their own business.

\section{Method}

Subjects and data collection process

Data were collected from a sample of 40 entrepreneurship students enrolled in three different programs, all situated in Sweden:

(1) Group 1: 13 business students undergoing a one-year master's program in entrepreneurship at Gothenburg School of Economics;

(2) Group 2: 19 engineering students undergoing a one-and-a-half-year master's program in entrepreneurship at Chalmers University of Technology; and

(3) Group 3: 8 students with diverse background, undergoing a one to one-and-a-half-year master's program in entrepreneurship at Borås University College.

We also collected data on a control group of 38 students enrolled in two other graduate programs in Sweden:

(1) Group 4: 18 medical students, undergoing a one to one-and-a-half-year master's program in biomedicine at Karolinska Institutet; and

(2) Group 5: 20 business students undergoing a one to one-and-a-half-year master's program in IT and business development or logistics and business development at Södertörn College.

We collected the primary data through a primary survey in the form of self-administered questionnaires, with the creativity test as a supplement. All students completing the questionnaire also completed the creativity test. The questionnaires were distributed to the students at their schools' locations, and filled out with one of the researchers present in order to answer questions. We were careful to tell all students that there were no "right" or "wrong" answers and that they would not be evaluated as individuals in any way. In addition, we conducted interviews with 23 of the students. Two students out of group 1, three students in group 2, one student in group 3 and four students in group 4 were unable to complete the questionnaire. Since all of these stated reasonable grounds for not participating (e.g. dentist appointment, picking up children at day-care), we can think of no reason why they would be particularly different on variables than the rest of the groups, although we have no way of measuring whether this is indeed the case or not. The study is based upon the assumption that we have a non-biased sample of entrepreneurship students in the
Creativity in entrepreneurship education

309 
JSBED

15,2

\section{0}

relevant programs. The respondents' average age was 27 years and 46 percent were females. Students had the following undergraduate majors:

- business or economics, 37.2 percent;

- engineering, 32.1 percent;

- natural sciences, 24.4 percent; and

- humanities and other subjects, 2.6 percent.

Concepts, variables and measures

Dependent variable. To measure entrepreneurial intention, respondents were asked to answer the question "How would you estimate the probability that you will run your own company in five years?" using seven-point Likert scales (1-7 denoting very low to very high probability). The operationalization was taken from prior studies of entrepreneurial intentions (Kolvereid, 1996, Krueger et al., 2000). As a validity measure for the intention variable, we also included two open-ended questions on future career goal. The answers to these two questions complement the main question on entrepreneurial intentions. Moreover, the two questions served as a good introduction to a topic and gave us some insight into the reasons of students wishing or not wishing to start their own business. In the result section, we perform a more rigorous validity analysis by re-coding the qualitative question and comparing these to the Likert-scale intention variable.

The entrepreneurship student is our first independent variable. Since we collected data from students enrolled in five different educational programs, we denoted students in entrepreneurship programs $(n=40)$ "one" and students in other programs $(n=38)$ "two", to create a dummy variable $(0 ; 1)$. Prior exposure to entrepreneurship, i.e. our socialization-related variables, were measured as dichotomous indicators: respondents were asked whether they themselves, family members, or friends/relatives had been running their own business (Chen et al., 1998). We coded the answers as dummy variables $(0 ; 1)$, "zero" value denoting no experience, and "one" denoting existing experience from entrepreneurship.

Creativity. Several different ways to assess creativity exist, including experiments (Ward, 2004), assessment of creative tasks based on observations (Amabile, 1996) and various tests (Amabile, 1996). We decided that a well-established psychometric test would be the best way to test for creativity among a set of groups. This was because experiments and assessments of creative outcomes (i.e. products/ideas produced by subjects and judged by a body of knowledgeable people) by far exceed the time and resources available, especially in regard to getting appropriate subjects to volunteer. Psychometric tests based on personality factors have been found generally to have high test-retest reliability (0.60-0.70) and moderate external validity $(0.20-0.55)$ as well as resemblance to real-life situations (0.25-0.50) (Cropley, 2000). We used the widely available $16 \mathrm{PF}$ personality test, which consists of a multitude of questions on a multiple-item scale $(1,2,3)$. Prior studies which have used $16 \mathrm{PF}$ to assess creativity concluded that five factors correlated positively with other measures of creativity: "Dominance", "Social boldness", "Abstractedness", "Openness to change" and "Perfectionism" (Conn and Rieke, 1994). Consequently, we pooled these five factors to create a continuous scale (0-10) as a measure of the students' creativity (relative to that of the other students, since we do not have a norm value comparable to other 
groups or the general population). Perception of risk as three entrepreneurial self-efficacy variables (perception of administrative difficulties, marketing difficulties, and workload in entrepreneurship) were similarly scaled on a Likert seven-point scale (from "very low" to "very high"). The perception of risk followed Miller and Friesen (1982) with the question "How do you estimate the financial risks for your private economy to start up and run your own business?"

Perception of administrative difficulties was measured by the question "How would you estimate the administrative difficulties like paperwork, patent and permission, bookkeeping and accounting with starting up and running your own business?", based on "management" factors' loading of entrepreneurial tasks examined in an earlier study (Chen et al., 1998).

Perception of marketing difficulties is based on "marketing" factors, also examined by Chen $e t$ al. (1998). In the questionnaire this is represented by: "How would you estimate the difficulty for reaching out the market with your service or product?"

Perception of workload in entrepreneurship was measured similarly to Wiklund et al. (2003) with the question "How would you estimate your future workload with starting up and running your own business?"

\section{Control variables}

Five variables were used as control variables. Respondents were asked to state their gender, age, number of higher education semesters, undergraduate major, and high school grades. The answers were coded as separate variables.

\section{Statistical analyses}

Our hypotheses were investigated through analysis of variance (ANOVA) and multivariate linear and ordinal regression analyses. Before analyzing the data we verified that the variable for entrepreneurial intention was normally distributed[1]. Table I shows the variables together with their summary statistics and correlations. Several variables are positively (being entrepreneurship student, personal experience of entrepreneurship, creativity) or negatively (being female, perception of financial risk, marketing risk and administrative difficulties) correlated with the dependent variable. Some of the independent variables are correlated with each other. In all regression models we therefore examined variance inflation (VIF) figures for the coefficients. Since these ranged from 1.04 to 1.45 , well below critical values, we have no reason to suspect that the presence of multicolinearity might impede our results.

\section{Results}

As can be seen in Table II, entrepreneurial intentions differed between the five student groups. The three groups of entrepreneurship students all have a higher mean score than group 4 (biomedical students) and group 5 (business students). The largest difference is between group 4 and the other groups. This indicates that type of education (i.e. engineering/business versus medicine) might also be a strong determinant of entrepreneurial intention such as being enrolled in an entrepreneurship program or not. A between-group analysis of variance (ANOVA) showed significant differences $f(4)=13,21 p<0.001$ from the post-hoc test revealing that the mean score for students in group 5 (business) was significantly $(p<0.05)$ lower than for all the other groups. The mean score for group 4 (biomedicine) was, in

\section{Creativity in entrepreneurship education}

311 
JSBED

15,2

312

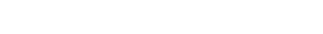

Table I.

Variables and correlation matrix

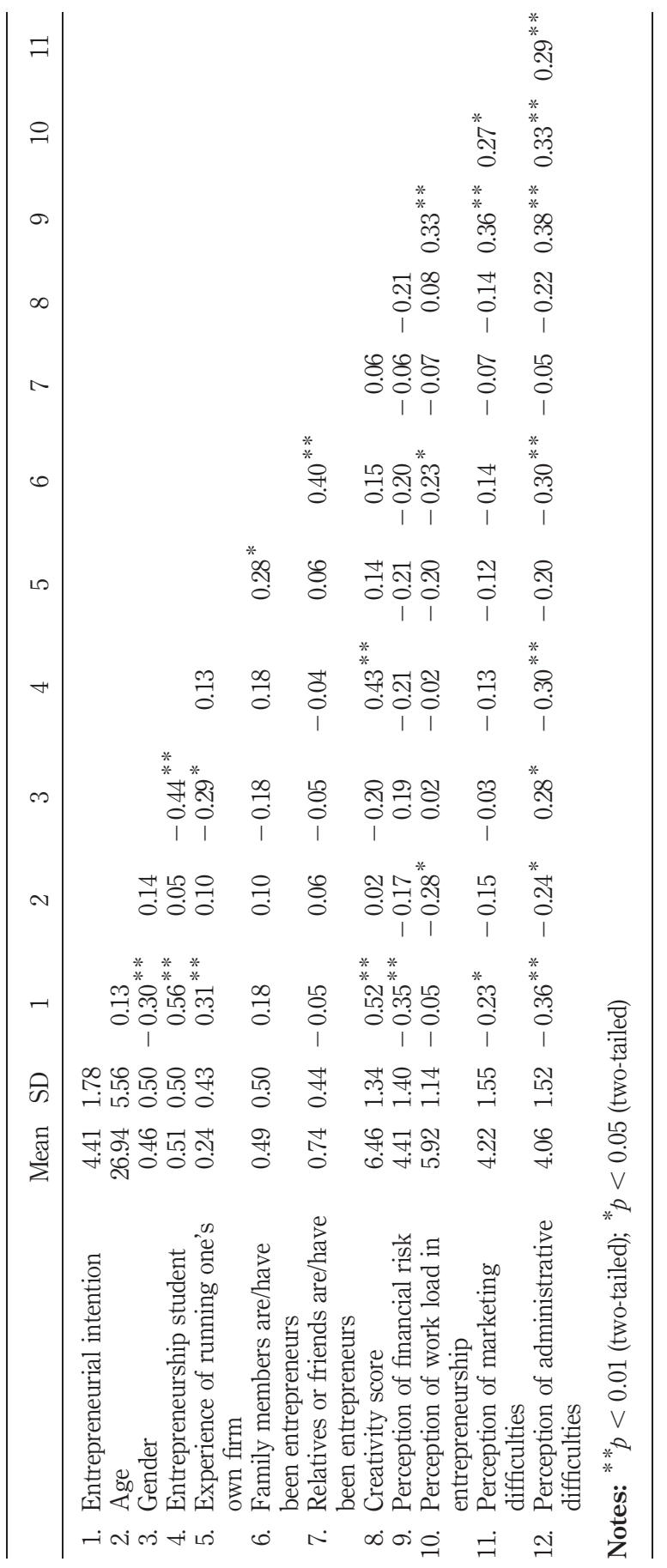


addition to being significantly higher than for group 5 , significantly lower than group for 1 . We can conclude that there are some important differences between the groups investigated. We now turn to testing our theoretically derived hypotheses in multivariate regression analyses.

\section{Regression analysis}

To test our hypotheses we regressed the independent variables in step-wise models, starting with the control variables and the entrepreneurship education variable in a first Model 1. The regression models with coefficients are displayed in Table III. We see in this model that being in one of the entrepreneurship education groups indicates a strong positive effect on entrepreneurial intention. We therefore find support for $H 1$. Introducing the socialization theory variables (the individual's, family's and close friends' former entrepreneurial experiences), in a second Model 2, reveals that entrepreneurial experience has a significant and fairly strong positive effect on current intention to start one's own business. We thus find support for H3. However, access to family members with experience in entrepreneurship shows no effect on entrepreneurial intention, nor does access to relatives or close friends, leading us to reject $H 4 a$ and $H 4 b$. Introducing the creativity score in a Model 3 , we find this to have a strong and positive effect on entrepreneurial intentions, leading us to affirm $H 2$. The influence of the creativity variable also notably increases our overall model fit. However, it decreases the influence of prior entrepreneurial experience, which now is significant only on the 10 percent level. Model 4 introduces the risk perception variable. This reveals a comparatively weak negative influence on entrepreneurial intentions, significant only at the 10 percent level. However, when introducing the three other attitude variables (perception of work load in entrepreneurship, marketing difficulties, and administrative difficulties) in Model 5 , the effect of risk perception is cancelled out. The results are somewhat ambiguous since the overall model fit (adjusted $R^{2}$ ) increases from 0.41 in Model 3 to 0.43 in Model 4, but then decreases to 0.42 in Model 5 . None of the three other attitude variables (our proxies for entrepreneurial self-efficacy) reveal a significant influence on the dependent variable, although the directions should be noted.

Checking for problems with colinearity[2] in Model 4, risk perception is the only variable with a condition index higher than 15 . The same check in Model 5 reveals several values above 15 for the four perception questions. It is necessary to deal with this problem before answering $H 5$ as well as determining the best overall model estimate. Since all of these variables are ordinal scaled with rather high mean values (see Table I), there is a possibility that the influence on the dependent variable is strongly influenced by a certain range of these independent variables. This indicates a

\begin{tabular}{lccr}
\hline Group & Mean & SD & $n$ \\
\hline Gothenburg School of Economics & 5.08 & 1.61 & 13 \\
Chalmers University of Technology & 5.42 & 1.12 & 19 \\
Borås University College & 5.75 & 1.28 & 8 \\
Karolinska Institutet & 2.56 & 1.72 & 18 \\
Södertörn College & 4.15 & 1.18 & 20 \\
Total & 4.41 & 1.78 & 78
\end{tabular}

Creativity in entrepreneurship education

313

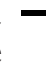


JSBED

15,2

314

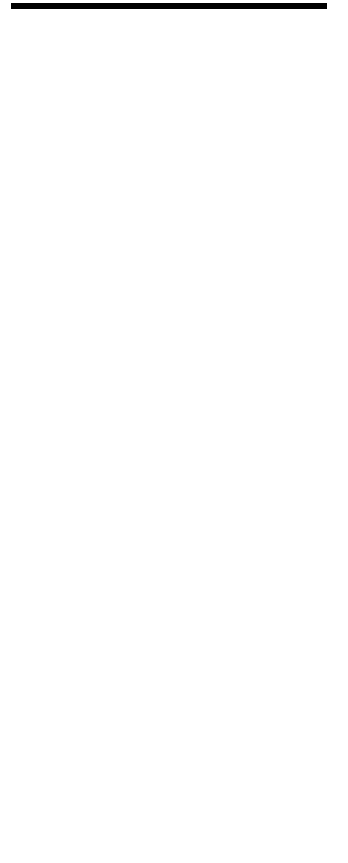

Table III.

Regression models and coefficients (std error in parentheses)

$$
\begin{aligned}
& \text { 吾葋 }
\end{aligned}
$$

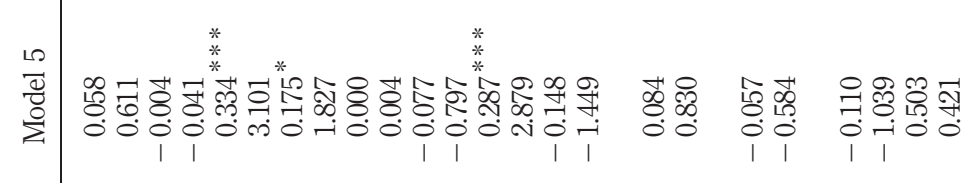

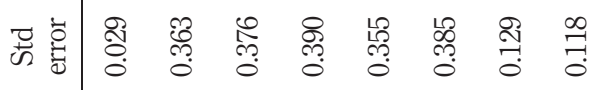

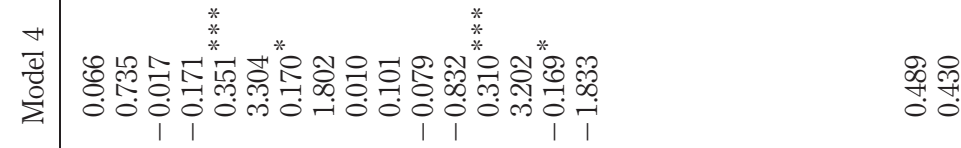

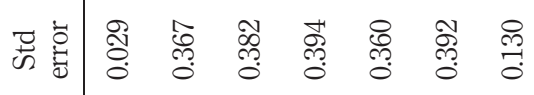

$$
\begin{aligned}
& \text { थ }
\end{aligned}
$$

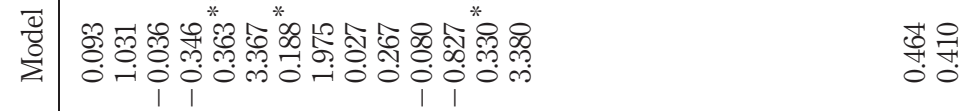

$$
\begin{aligned}
& \text { 荧苞 }
\end{aligned}
$$

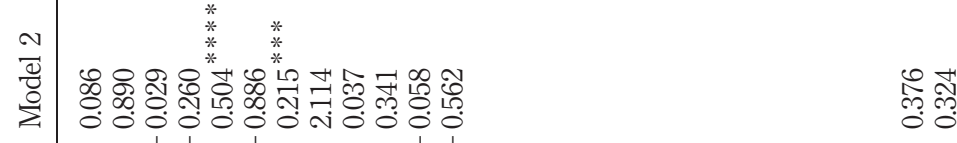

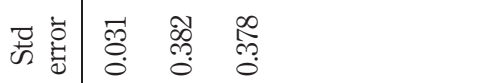

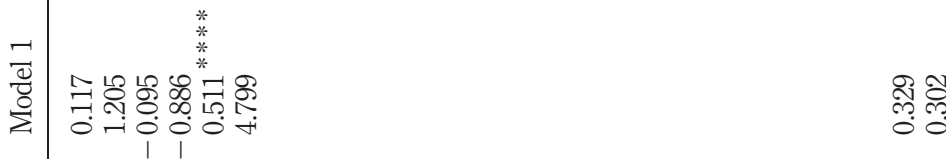

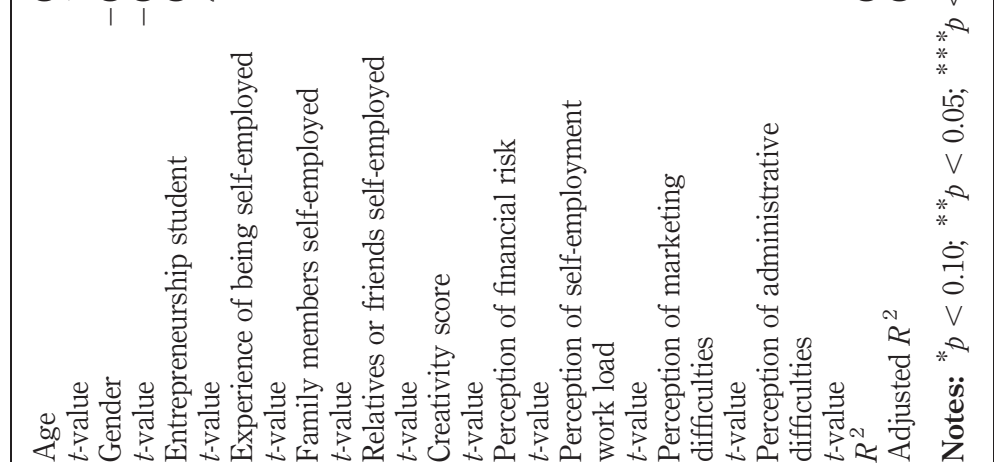


violation in the assumption of the linear regression model, which is that all ordinal variables are evenly distributed. We therefore re-estimated Models 4 and 5, using an ordinal regression (McCullagh and Nelder, 1989). Ordinal regressions treat each ordinal value as an independent variable in itself. Thus we can examine parameter estimates for a certain range of values within an independent variable, a valuable method if we suspect that answers on the ordinal scale attitude variable might influence the dependent variable only within a certain threshold level. We used the same variables as in Model 4 in the linear regression, but excluded the control variable of age with an interval scale. Since the creativity score is in interval range, we re-coded it into a dummy variable $(0 ; 1)$, where a score equal to or higher than 7 ( $n=36$ percent) was coded " 1 ", the lower scores being coded " 0 "[3].

The result of the ordinal regression model is shown in Table IV. Re-estimating Model 4 of the linear regression model, the ordinal regression in Table IV reveals a higher model fit, significantly outperforming the initial linear regression model above a one percent significance level[4]. Outputs for Pearson (0.315) and deviance (0.00) both suggest that the model adequately fits the data. This effect is mainly due to the lower levels of risk perception (1;2 out of 7 ) having a positive effect, i.e. that low levels of risk perception are positively associated with entrepreneurial intention, thus affirming H5. However, in the ordinal regression model the creativity variable is only a modest predictor of intention towards entrepreneurship, with a significance level of 0.065 .

Notes: ${ }^{*} p<0.10 ;{ }^{* *} p<0.05 ;{ }^{* * *} p<0.01 ; * * * p<0.001$

\begin{tabular}{|c|c|c|c|}
\hline Coefficient and ordinal level & Wald & Std error & $n$ \\
\hline Entrepreneurial intention $=1$ & $6.930 * * *$ & 1.291 & 8 \\
\hline Entrepreneurial intention $=2$ & $4.896^{* *}$ & 1.275 & 4 \\
\hline Entrepreneurial intention $=3$ & 1.959 & 1.254 & 10 \\
\hline Entrepreneurial intention $=4$ & 0.114 & 1.237 & 15 \\
\hline Entrepreneurial intention $=5$ & 0.789 & 1.239 & 18 \\
\hline Entrepreneurial intention $=6$ & $4.100 * *$ & 1.266 & 13 \\
\hline Gender $=0$ (male) & 0.025 & 0.517 & 42 \\
\hline $\begin{array}{l}\text { Experience of running one's own firm }=0 \text { (no } \\
\text { experience) }\end{array}$ & $4.154^{* *}$ & 0.556 & 59 \\
\hline $\begin{array}{l}\text { Family members are/have been entrepreneurs }=0 \\
\text { (none) }\end{array}$ & 0.207 & 0.488 & 40 \\
\hline $\begin{array}{l}\text { Relatives or friends are/have been entrepreneurs }= \\
0 \text { (none) }\end{array}$ & 0.124 & 0.536 & 20 \\
\hline Creativity score $=0$ (lower than 7 out of 10$)$ & $3.494^{*}$ & 0.475 & 30 \\
\hline Perception of financial risk $=1$ & $5.217^{* *}$ & 1.553 & 4 \\
\hline Perception of financial risk $=2$ & $2.743^{*}$ & 1.793 & 2 \\
\hline Perception of financial risk $=3$ & 1.235 & 1.244 & 13 \\
\hline Perception of financial risk $=4$ & 2.344 & 1.207 & \\
\hline Perception of financial risk $=5$ & 0.725 & 1.184 & 24 \\
\hline Perception of financial risk $=6$ & 0.417 & 1.265 & 14 \\
\hline $\begin{array}{l}\text { Entrepreneurship student }=0 \text { (not } \\
\text { entrepreneurship student) }\end{array}$ & $13.945 * * * *$ & 0.600 & 38 \\
\hline Psedu $R^{2}$ (Cox and Snell) & 0.472 & & \\
\hline Psedu $R^{2}$ (Negelkerke) & 0.483 & & \\
\hline
\end{tabular}

\section{Creativity in entrepreneurship education}

315
Table IV. Ordinal regression models with Wald coefficients (std error in parentheses) 
JSBED

15,2

316
Since all our analyses are based on the same dependent variable measured by a single item in the questionnaire, results and interpretations rely on the assumption that all subjects understood the question correctly and answered honestly. To some extent our results might therefore be susceptible to common method bias. To remedy this problem, we used the two open-ended questions mentioned in the theory section to validate our measure of entrepreneurial intentions. We coded these two questions into ordinal variables (1;2;99), "1" for an answer suggesting that the student's foremost career choice in the near future would be to run their own firm, "2" that it would not be, and "99" for missing or ambiguous answers. We then cross-checked these two new variables with the dependent variable. If intention was clearly not on the higher scale $(<4)$, we checked that the answer to the two questions had been coded as "2". If intention was clearly not on the lower scale $(>3)$ we checked that the answer to the two questions had been coded as "1". This resulted in eight cases where one or both of these questions could be interpreted as being in opposition to the answer for the 7-scale dependent variable. After re-estimating all models while excluding these eight cases, the only difference was that risk perception was significant at the 10 percent level.

\section{Discussion}

One of the most interesting findings in this study is the surprisingly strong influence of our measure of personal creativity on entrepreneurial intentions. However, our results should be seen as tentative at this point, since personality theories are intended to measure broad personality constructs stable across various environments and situations, and as such are weak determinants of specific behavior (Wiklund et al., 2003). Additional research on the creative dispositions among entrepreneurship students is necessary to confirm our findings. Preferably, such investigations should consider the wide range of measures in creativity assessments (Amabile, 1996).

We also found that students engaged in academic entrepreneurship programs have higher intentions to start their own businesses in the future. However, the difference between entrepreneurship students and other students is smaller than the difference between those with a business or engineering degree and those with a degree in medicine. This indicates that important differences exist between how students in various areas perceive entrepreneurial opportunities in their future profession. Also, the fact that students engaged in an academic entrepreneurship program had higher intentions to start their own business might be a result of students with high entrepreneurial intentions self-selecting into these programs. In regard to future research, we believe it might be valuable to further examine the impact of different educational choices on the students' entrepreneurial intention. Specifically, it would be of value to examine entrepreneurial role models in each educational context, since our results indicate significant differences in entrepreneurship intention between different educational fields. Entrepreneurial activity depends not only on the desirability and feasibility of entrepreneurship, but also upon the desirability and feasibility of employment (Kolvereid, 1996). Therefore, it would also be interesting to investigate whether students with higher expectations on employment regard entrepreneurship as a less desirable alternative. 
Limitations

Using intentions as a dependent variable is not unproblematic. Even though intentions are considered a stronger predictor (or, in other words, mediator of the impact of attitudes) of actual behavior than, for example, personality (Bandura, 1986), this predictive ability might vary between individuals, in that some people are more likely to go about actually fulfilling their intentions while some are not. In other words, by using intentions as a measure of future behavior, a clear risk is that we cannot differentiate between "dreamers" and “doers" (Delmar and Davidsson, 2000).

\section{Implications for theory about intentions and entrepreneurial behavior}

To the best of our knowledge, this study is the first to investigate the role of creativity in entrepreneurial intentions. Our study therefore offers contributions to the literature on entrepreneurial intentions (Krueger and Brazeal, 1994) and entrepreneurship as a career choice (Kolvereid, 1996). One reason for the large impact of creativity compared to other factors could be that creativity as a concept is more proactively oriented than factors such as perceived behavioral control, perceived social norms and risk-taking propensity. While these factors might be good indicators for why students will see entrepreneurship as a feasible employment alternative, creativity may more specifically and proactively influence entrepreneurial behavior in terms of innovation, product development, marketing etc. Since creativity appears to be strongly associated with entrepreneurial intentions, future studies might benefit from drawing upon the rich literature on creativity in psychology and other social sciences. Nyström (1993) suggested that the creative efforts emphasized "openness" and "closure" during different phases of a new venture's lifetime. Similarly, Sarasvathy (2001) suggested that creative reasoning might be more prevalent in dynamic industries than in stable industries. Berglund and Wennberg (2006) found significant differences in creativity style between entrepreneurship students with engineering or business school training, suggesting that creativity can be affected by different educational efforts. These and other studies offer intriguing opportunities for future research on the intersection of creativity, intentions, and entrepreneurship education.

\section{Implications for entrepreneurship education}

Our findings on the role of creativity for entrepreneurial intentions also have implications for entrepreneurship education. To the extent that educational programs seek to mix different student groups, it is vital to know how students differ in creative potential and how one may mix them to aid joint learning and prevent potential barriers to learning. The open-ended questionnaire items and interview data indicated heterogeneity in creative styles among the students, which indicates that a "one-size-fits-all" approach to entrepreneurship education is problematic (see Hytti and Kuopusjärvi, 2004). To benefit various students' style of creativity, entrepreneurship education should therefore to a larger extent focus on prowess in team working, divergent thinking, and interpersonal communication (Gundry and Kickul, 1996; Winslow and Solomon, 1987). By integrating creativity approaches and skills into entrepreneurship education, students will gain new and much-needed skills to interact with the dynamic marketplace of today.

\section{Creativity in entrepreneurship education}

317 
JSBED

15,2

318

\section{Conclusions}

In this paper we have studied the role of career experiences and personal creativity for developing entrepreneurial intentions in a sample of 40 students enrolled in a graduate entrepreneurship education program and a control group of 38 students enrolled in other graduate programs. Using linear and ordinal regression analyses, we found that high scores on a creativity test and prior entrepreneurial experiences are positively associated with entrepreneurial intentions, indicating that creativity should be considered in theoretical models of entrepreneurial intentions. Further, we found that students engaged in academic entrepreneurship programs had higher intentions to start their own businesses in the future. We used these findings to discuss the role of entrepreneurship education for developing entrepreneurial intentions as well as realized entrepreneurship. To benefit various students' style of creativity, entrepreneurship education should focus on prowess in team working, divergent thinking, and interpersonal communication.

\section{Notes}

1. A Chi-square "goodness-of-fit" test was deemed inappropriate because of the small sample, and we relied instead on a Kolmogorov-Smirnov test which confirmed that our dependent variable is normally distributed.

2. Condition index above 15 indicates a possible problem with colinearity; above 30 indicates a serious problem.

3. We consciously put the value quite high to examine whether a high creativity score would have the same strong influence as the independent interval variable in the linear regression models.

4. The $R$-square statistic cannot be exactly computed for ordinal regression models, so instead pseudo-approximations, indicating that more of the variation (from 0 to 1 ) in the response is explained by the model, are computed. Our model shows balanced values for Cox and Snell (0.472) and Negelkerke (0.483).

\section{References}

Amabile, T.M. (1996), Creativity in Context, Westview Press, Boulder, CO.

Bandura, A. (1986), Social Foundations of Thought and Action, Prentice-Hall, Englewood Cliffs, NJ.

Berglund, H. and Wennberg, K. (2006), “Creativity among entrepreneurship students: comparing engineering and business education", International Journal of Continuing Engineering Education, Vol. 16 No. 5, pp. 366-79.

Bird, B.J. (1989), Entrepreneurial Behavior, Scott Foresman and Co., Glenview, IL.

Boyd, N.G. and Vozikis, G.S. (1994), "The influence of self-efficacy on the development of entrepreneurial intentions and actions", Entrepreneurship Theory and Practice, Vol. 18 No. 4, pp. 63-77.

Busenitz, L.W., West, I., Page, G., Shepherd, D., Nelson, T., Chandler, G.N. and Zacharakis, A. (2003), "Entrepreneurship research in emergence: past trends and future directions", Journal of Management, Vol. 29 No. 3, pp. 285-308.

Chen, C., Greene, P. and Crick, A. (1998), "Does entrepreneurial self-efficacy distinguish entrepreneurs from managers?”, Journal of Business Venturing, Vol. 13, pp. 295-316.

Conn, S.R. and Rieke, M.L. (1994), The 16PF Fifth Edition Technical Manual, Institute for Personality and Ability Testing, Champaign, IL. 
Cropley, A.J. (2000), "Defining and measuring creativity: are creativity tests worth using?", Roeper Review, Vol. 23, pp. 72-81.

Davidsson, P. (1991), "Continued entrepreneurship: ability, need, and opportunity as determinants of small firm growth", Journal of Business Venturing, Vol. 6, pp. 405-29.

Davidsson, P. (2002), "What entrepreneurship research can do for business and policy practice", International Journal of Entrepreneurship Education, Vol. 1, pp. 5-24.

Delmar, F. and Davidsson, P. (2000), "Where do they come from? Prevalence and characteristics

Creativity in entrepreneurship education

319

Fayolle, A. (2005), "Evaluation of entrepreneurship education: behaviour performing or intention increasing", International Journal of Entrepreneurship and Small Business, Vol. 2 No. 1, pp. 89-98.

Gundry, L. and Kickul, J. (1996), "Flights of imagination: fostering creativity through experiential learning”, Simulation Gaming, Vol. 27, pp. 334-49.

Hills, G.E. (1988), "Variations in university entrepreneurship education: an empirical study of an evolving field”, Journal of Business Venturing, Vol. 3 No. 3, pp. 109-22.

Hytti, O. and Kuopusjärvi, P. (2004), "Evaluating and measuring entrepreneurship and enterprise education: methods, tools and practices", working paper, Small Business Institute, Turku Schools of Economics and Business Administration, Turku.

Johannisson, B., Landström, H. and Rosenberg, J. (1998), "University training for entrepreneurship - an action frame of reference", European Journal of Engineering Education, Vol. 23 No. 4, pp. 477-96.

Katz, J.A. (1992), "A psychosocial cognitive model of employment status choice", Entrepreneurship Theory and Practice, Vol. 17 No. 1, pp. 29-37.

Kolvereid, L. (1996), "Prediction of employment status choice intentions", Entrepreneurship Theory and Practice, Vol. 21, pp. 47-57.

Krueger, N.F. and Brazeal, D.V. (1994), "Entrepreneurial potential and potential entrepreneurs", Entrepreneurship Theory and Practice, Vol. 19, pp. 91-104.

Krueger, N.F., Reilly, M.D. and Carsrud, A.L. (2000), "Competing models of entrepreneurial intentions", Journal of Business Venturing, Vol. 15, pp. 411-32.

McCullagh, P. and Nelder, J. (1989), Generalized Linear Models, Chapman and Hall, New York, NY.

Miller, D. and Friesen, P.H. (1982), "Innovation in conservative and entrepreneurial firms: two models of strategic momentum", Strategic Management Journal, Vol. 3, pp. 1-25.

Nyström, H. (1993), "Creativity and entrepreneurship", Creativity and Innovation Management, Vol. 2 No. 4, pp. 237-42.

Palich, L. and Bagby, D. (1995), "Using cognitive theory to explain entrepreneurial risk-taking: challenging conventional wisdom”, Journal of Business Venturing, Vol. 10 No. 6, pp. 425-38.

Sarasvathy, S.D. (2001), "Causation and effectuation: toward a theoretical shift from economic inevitability to entrepreneurial contingency", Academy of Management Review, Vol. 26 No. 2, pp. 243-63.

Solomon, G. and Fernald, L. (1991), "Trends in small business management and entrepreneurship education in the United States", Entrepreneurship Theory and Practice, Vol. 15, pp. 25-39.

Solomon, G., Duffy, S. and Tarabishy, A. (2002), "The state of entrepreneurship education in the United States: a nationwide survey and analysis", International Journal of Entrepreneurship Education, Vol. 1 No. 1, pp. 65-86. 
JSBED

15,2

320
Souitaris, V., Zerbinati, S. and Al-Laham, A. (2007), "Do entrepreneurship programmes raise entrepreneurial intention of science and engineering students? The effect of learning, inspiration and resources", Journal of Business Venturing, Vol. 22 No. 4, pp. 566-91.

Storey, D. (2000), "Six steps to heaven: evaluating the impact of public policies to support small businesses in developed economies", in Sexton, D.L. and Landström, H. (Eds), The Blackwell Book of Entrepreneurship, Blackwell, Oxford, pp. 176-94.

Thurik, R. and Wennekers, S. (2004), "Entrepreneurship, small business and economic growth", Journal of Small Business and Enterprise Development, Vol. 11 No. 1, pp. 140-9.

Ward, T.B. (2004), "Cognition, creativity, and entrepreneurship", Journal of Business Venturing, Vol. 19, pp. 173-88.

Westhead, P. (2003), "Company performance and objectives reported by first and multi-generation family companies", Journal of Small Business and Enterprise Development, Vol. 10 No. 1, pp. 93-105.

Wiklund, J., Davidsson, P. and Delmar, F. (2003), "What do they think and feel about growth? An expectancy-value approach to small business managers' attitudes toward growth", Entrepreneurship Theory and Practice, Vol. 27 No. 3, pp. 247-70.

Wilson, K. (2004), "Entrepreneurship education at European universities and business schools", working paper, European Foundation for Entrepreneurship Research, Hilversum.

Winslow, E.K. and Solomon, G.T. (1987), "Entrepreneurs are more than non-conformists: they are mildly sociopathic", Journal of Creative Behavior, Vol. 21 No. 3, pp. 202-13.

Zeithaml, C.P. and Rice, G.H. Jr (1987), "Entrepreneurship/small business education in American universities", Journal of Small Business Management, Vol. 25 No. 1, pp. 44-50.

\section{Further reading}

Kolvereid, L. and Moen, O. (1997), "Entrepreneurship among business graduates: does a major in entrepreneurship make a difference?", Journal of European Industrial Training, Vol. 21, pp. 154-60.

\section{Corresponding author}

Daniel Yar Hamidi can be contacted at: daniel.yar@hb.se

To purchase reprints of this article please e-mail: reprints@emeraldinsight.com Or visit our web site for further details: www.emeraldinsight.com/reprints 